\title{
INGLÊS NA ESCOLA PÚBLICA: experiências com tecnologias digitais, inclusão, autoria docente e discente
}

\section{ENGLISH IN PUBLIC SCHOOLS: experiences with digital technologies, inclusion, teacher and student authorship}

\begin{abstract}
Viviane C. Bengezen ${ }^{52}$
RESUMO: Nesta pesquisa narrativa, meu foco são as histórias individuais de quatro alunos do sexto ano, vividas quando eles foram autores de textos em inglês e de suas vidas na paisagem de uma escola pública. Considero relevante narrar as histórias desses jovens brasileiros, pelo modo como utilizaram as tecnologias digitais em diferentes espaços no currículo, vivendo e narrando histórias que não eram de fracasso, apesar dos obstáculos que tiveram que enfrentar. Adotando o conceito de ética relacional como pressuposto, apresento parte dos resultados da minha pesquisa de doutorado, que foi realizada em uma escola de Minas Gerais, agora com foco nas tecnologias digitais, inclusão e ética relacional. Indo de encontro a histórias de fracasso, reclamação, marginalização e desistência que tenho ouvido durante meu percurso profissional na área de ensino de línguas na escola pública, meu objetivo neste trabalho é refletir sobre as possibilidades e convidar à imaginação de histórias futuras de honra, aprendizagem, persistência, inclusão, pertencimento e autoria nas aulas de língua inglesa em escolas públicas brasileiras, narrando as histórias que nos constituem e como cada um entendeu as experiências de autoria em língua inglesa, utilizando tecnologias digitais nas aulas de Inglês de uma escola pública mineira. Entre as contribuições para a área da Linguística Aplicada, considero as discussões sobre o uso das tecnologias digitais para produção de textos em língua inglesa, criando oportunidades de pertencimento dos alunos e o trabalho com gêneros para ensinar e aprender inglês. Os resultados dessa pesquisa foram: (1) A inclusão dos alunos foi possível porque utilizamos as tecnologias digitais para criarmos um sentimento coletivo de pertencermos a uma comunidade de construção de conhecimento (2) Eu, como professora, vivi histórias de autoria docente à medida que os alunos compuseram histórias de autoria discente, sempre considerando a ética relacional da pesquisa narrativa.
\end{abstract}

PALAVRAS-CHAVE: Tecnologias digitais. Ensino de língua inglesa. Autoria. Ética relacional.

ABSTRACT: In this narrative inquiry, my focus is on the individual stories of four grade six English as a Foreign Language students, lived when they were authors of texts in English and their lives on the landscape of a public school. I consider it relevant to tell the stories of these young Brazilians, the way they used digital technologies in different places in the curriculum, living and telling stories that were not of failure, despite the obstacles they had to face. Adopting the concept of relational ethics, I present part of the results of my $\mathrm{PhD}$ research, which was carried out in a school in Minas Gerais, now focusing on digital technologies, inclusion and relational ethics. Going against the stories of failure, complaint, marginalization and withdrawal that I have heard during my professional career in the field of language teaching in public schools, this work aims at reflecting on the possibilities and invites to imagination of future stories of honor, learning, persistence, inclusion, belonging and authorship. I share our stories to live by and our experiences as we become Englishlanguage authors using digital technologies in English-language classes of a public school in Minas Gerais. Among the contributions to the field of Applied Linguistics, I consider the discussions about the use of digital technologies for English language production, creating opportunities for students to belong and working with genres to teach and learn English. The results of this research were: (1) Inclusion of students was possible because we used digital technologies to create a collective feeling of belonging to a knowledge-building community. (2) As a teacher, I experienced stories of teacher authorship as the students composed stories of student authorship, always considering the relational ethics of narrative inquiry.

KEYWORDS: Digital Technologies. English Teaching. Authorship. Relational Ethics.

\footnotetext{
52 Doutora em Estudos Linguísticos (UFU). Professora da Unidade Acadêmica Especial de Letras e Linguística e do Programa de Pós-Graduação em Estudos da Linguagem da Universidade Federal de Goiás (UFG), Regional Catalão. E-mail: vbengezen@gmail.com
} 


\title{
1 Introdução
}

Quando entrei em campo de pesquisa na Escola Aquarela em fevereiro de 2014, eu tinha um projeto de doutorado e um foco principal: honrar as histórias que eu e meus alunos viveríamos na escola pública brasileira. Considerando a área da Linguística Aplicada, cujo objeto é a linguagem em uso, decidi trilhar o caminho teórico e metodológico da pesquisa narrativa conforme Clandinin e Connelly $(2000,2015)$ para investigar um objeto específico: as experiências de autoria vividas pelos alunos do sexto ano nas aulas de língua inglesa e por mim, na época, professora da educação básica.

A concepção de autoria, neste estudo, foi construída com base nos conceitos de voz e assinatura conforme Clandinin e Connelly (2000) e Mello (2004, 2007, 2012, 2013), isto é, a produção dos textos com a marca da identidade do autor, que são as histórias que o constituem $^{53}$. Conforme afirmei em Bengezen (2017), ao viver e narrar as histórias de autoria docente e discente, a concepção de autoria pode ser entendida na relação entre minhas experiências de autoria docente e as experiências de autoria discente dos alunos participantes de pesquisa. Essas experiências de autoria estavam conectadas com experiências de singularidade, liberdade e criatividade, sempre compreendidas como processo e considerando várias tentativas, em um constante tornar-se. Mais importante do que conceituar autoria, ter desenvolvido uma pesquisa narrativa em uma escola pública brasileira tornou possível discutir como cada um de nós, alunos e professora, narrou suas próprias experiências de autoria.

Embora eu tivesse enfrentado muitos desafios como professora e como pesquisadora, meu compromisso ontológico com os jovens brasileiros ficava constantemente acima do epistemológico. Entendo que destacar esse fato é fundamental para que eu me posicione quem sou e quem estou me tornando como formadora de professores de línguas, atualmente trabalhando em um curso de Letras no Brasil, e também para chamar a atenção para a ética relacional (CLANDININ, et al, 2018; BENGEZEN, 2018), conceito base para a pesquisa narrativa.

Adotando o conceito de ética relacional como pressuposto, apresento parte dos resultados da minha pesquisa de doutorado, que foi realizada em uma escola de Minas Gerais. Meu objetivo neste trabalho é refletir sobre as possibilidades e convidar à imaginação de histórias futuras de honra, aprendizagem, persistência, inclusão, pertencimento e autoria nas aulas de língua inglesa em escolas públicas brasileiras, narrando as histórias que nos constituem (eu, professora de língua inglesa e meus alunos do sexto ano Everton, Lowise, Manoela e Kamilly Vitória ${ }^{54}$ ) e como cada um entendeu as experiências de autoria, utilizando tecnologias digitais nas aulas de Inglês de uma escola pública mineira.

Connelly e Clandinin (2006, p. 375) afirmam que

\begin{abstract}
As pessoas formam suas vidas por meio de histórias sobre quem elas e os outros são e sobre como elas interpretam seu passado em termos dessas histórias. A história é um portal através do qual a pessoa entra no mundo e pelo qual suas experiências são interpretadas e fazem sentido para ela. A pesquisa narrativa, o estudo da experiência como história, é um modo de pensar sobre a experiência. A pesquisa narrativa como metodologia implica uma visão sobre o fenômeno. Usar a metodologia da pesquisa narrativa é adotar uma visão particular da experiência como fenômeno sob estudo ${ }^{55}$ (minha tradução).
\end{abstract}

\footnotetext{
${ }^{53}$ Histórias que nos constituem (stories to live by) é um termo narrativo para identidade, conforme Connelly e Clandinin (1999).

${ }^{54}$ A presente pesquisa recebeu parecer favorável do Comitê de Ética em Pesquisa (CEP) da Universidade Federal de Uberlândia. O CEP apoiou a utilização dos nomes reais dos alunos, como forma de honrar sua autoria. Assim, sempre que possível, busco mencionar os nomes dos participantes de pesquisa, para destacar sua singularidade e importância como autores dos textos que criaram.

${ }_{55}$ Original: People shape their daily lives by stories of who they and others are and as they interpret their past in terms of these stories. Story, in the current idiom, is a portal through which a person enters the world and by
} 
De 2014 a 2017, eu e meus alunos nos engajamos narrativamente para buscar entender quem nós éramos e quem estávamos nos tornando na paisagem ${ }^{56}$ da escola, com foco na autoria em língua inglesa e no uso das tecnologias digitais. Ao prestar atenção a como eu, o Everton, a Lowise, a Manoela e a Kamilly Vitória vivemos nossas histórias, busco compreender como nós interpretamos o mundo, compusemos sentidos e que histórias de inclusão e autoria foram e continuam sendo construídas, a partir do meu olhar como formadora de professores de línguas.

Em 2014, eu era professora efetiva de uma escola municipal, e tinha oito turmas de Inglês do sexto ano. Ao final do ano, 126 alunos produziram textos em língua inglesa, cada um do gênero que tinha escolhido ser autor, que foram organizados em um e-book (BENGEZEN, 2016) e têm inspirado alunos, pais e professores envolvidos com ensino de línguas e formação de professores de línguas. A história que eu escolhi viver e contar é uma história de que é possível ser autor em língua inglesa na escola pública, é possível honrar as histórias dos participantes de pesquisa e de nossos alunos no curso de Letras e é relevante lutar por uma educação pública de qualidade.

Neste artigo, meu foco são as histórias individuais dos alunos Everton, Lowise, Manoela e Kamilly Vitória, quando eles foram autores de textos em inglês e de suas vidas na paisagem de uma escola pública, utilizando tecnologias digitais. Considero relevante contar e recontar as histórias desses jovens brasileiros, pelo modo como utilizaram as tecnologias digitais em diferentes espaços no currículo, vivendo e narrando histórias que não eram de fracasso, apesar dos obstáculos que tiveram que enfrentar. Quanto às experiências de autoria docente vivenciadas por mim e narradas detalhadamente em Bengezen (2017), foram histórias de tentativas de autoria, cujo foco era a produção oral e escrita em inglês, com base em gêneros. Utilizei os pressupostos teóricos de Cristóvão e Szundy (2008), Cristóvão e BeatoCanato (2016) e Beato-Canato e Cristóvão (2012), sobre avaliação de sequências didáticas, escrita, gêneros textuais, inglês para fins específicos e formação de professores, de Swales (1990, 2004, 2007), sobre análise e aplicação de gêneros, de Dolz e Schneuwly (2004), sobre sequências didáticas no ensino de línguas e de Beato-Canato (2009), sobre a escrita em inglês, na escola, com o uso de sequências didáticas.

$\mathrm{Na}$ primeira tentativa de autoria docente, criei espaços de aprendizagem de língua inglesa com base no gênero perfil. Na minha segunda tentativa de autoria, eu parti dos textos de crianças de uma escola do Reino Unido, disponíveis na internet. Na terceira tentativa de autoria da minha prática docente, vivi e contei a história de quando transformei minha prática sem buscar modelos, redefinindo o curso, por meio de um novo planejamento: cada aluno escolheu e decidiu qual gênero iria produzir, em inglês. Assim, nós co-compusemos novos sentidos para o processo de ensinar e aprender a língua inglesa, eu criei espaço para os alunos escolherem de que eles queriam ser autores e parei, de fato, para ouvir meus alunos (pela primeira vez).

\section{O caminho teórico e metodológico}

Entendo minha prática como professora e o uso das tecnologias digitais como construídos narrativamente. Assim como Connelly e Clandinin (1990), entendo a narrativa

\footnotetext{
which their experience of the world is interpreted and made personally meaningful. Narrative inquiry, the study of experience as story, then, is first and foremost a way of thinking about experience. Narrative inquiry as a methodology entails a view of the phenomenon. To use narrative inquiry methodology is to adopt a particular view of experience as phenomenon under study.

${ }^{56}$ Utilizo o conceito de paisagem baseada nas paisagens do conhecimento profissional dos professores conforme Clandinin e Connelly (1996), onde os professores vivem e narram histórias sagradas, secretas e de fachada.
} 
tanto como método, quanto como fenômeno. Meu interesse é nas experiências que as pessoas vivem e narram: compreendo a experiência e a estudo narrativamente, adotando uma concepção de experiência conforme Dewey (1938), considerando os critérios de experiência: continuidade e interação. Assim como Clandinin e Murphy (2009, p. 599) destacam, "três características de uma ontologia deweyana da experiência nos ajudam a estruturar a pesquisa narrativa: ênfase na dimensão social da pesquisa, temporalidade da geração do conhecimento e continuidade, que não é somente perceptível, mas ontológica ${ }^{57}$."

Compreender a experiência narrativamente significa que considero a experiência em relação ao espaço tridimensional da pesquisa narrativa, com suas dimensões de lugar, temporais e pessoais/sociais. Com esse espaço de pesquisa em mente, posso ver fios de experiência entrecruzados nas histórias que nos constituem na paisagem da escola. Fios narrativos, de acordo com Clandinin (2013), fazem parte das experiências vividas. Em vez de reduzir a experiência em categorias ou temas, o conceito de fios entende a complexidade da experiência ao longo de uma vida. Como Minh-ha (1989, p. 94) observa, "apesar das nossas tentativas desesperadas de separar, conter e medir, as categorias sempre escorrem"58.

Assim, na busca por compreender as experiências narrativamente, compus textos de campo durante o ano letivo de 2014, formados por notas de campo, diários reflexivos, diários de classe, materiais das aulas (atividades e avaliações) produzidos por mim, a professora, mensagens de WhatsApp, conversas do Facebook, fotografias e materiais produzidos pelos alunos (entregues escritos a mão ou postados na plataforma virtual que utilizamos - o Edmodo).

A partir dos textos de campo, passei a me mover deles para os textos de pesquisa (artigos, teses, livros etc.). Durante essa transição, escrevi textos de pesquisa intermediários, destacando momentos e lugares de tensão, e momentos quando nossas histórias davam uma guinada. Sempre considerando o espaço tridimensional da pesquisa narrativa, identifiquei fios narrativos que se entrelaçavam às histórias que eu, o Everton, a Manoela, a Lowise e a Kamilly Vitória vivemos e narramos e, imaginando a audiência e a relevância para a área da Linguística Aplicada, escrevi este artigo.

Considerando a ética relacional da pesquisa narrativa (CLANDININ, et al, 2018), e uma visão de conhecimento como pessoal, construído na experiência, corporificado e narrativo conforme Bruner (1986), Clandinin (2013), Clandinin e Connelly (1995), Clandinin et al. (2006) e Mello et al (2016), entendo que por meio de uma pesquisa colaborativa como a pesquisa narrativa, eu poderia pesquisar COM os alunos, em vez de pesquisar OS alunos. Essa perspectiva teórica e metodológica é coerente com meu objeto de estudo, que são as experiências de autoria com tecnologias digitais que vivemos na escola. Iniciei esta pesquisa perguntando-me sobre a composição de uma história para ser vivida, uma história para me constituir: como a autoria discente é assumida nas vidas dos jovens brasileiros nos contextos digitais onde vivemos e o que essas experiências com autorias e tecnologias digitais têm a nos ensinar?

Nas seções que se seguem, apresento os participantes de pesquisa, a fim de situar meu entendimento sobre como as tecnologias digitais podem apoiar a construção de identidades nas escolas. Depois, inicio uma discussão sobre o trabalho com gêneros no ensino de língua inglesa, por meio de tecnologias digitais. Então, foco nas experiências vividas por Lowise e como as tecnologias digitais ajudaram-na a promover uma conexão com a escola, promovendo sua inclusão à sala de aula, apesar de estar distante fisicamente. A seção seguinte

\footnotetext{
${ }^{57}$ Original: three features of a Deweyan ontology of experience are well suited for framing narrative research: emphasis on the social dimension of inquiry, temporality of knowledge generation, and continuity that is not merely perceptual but ontological.

${ }^{58}$ Original: despite our desperate, eternal attempt to separate, contain, and mend, categories always leak.
} 
inclui uma problematização sobre esses quatro alunos de sexto ano, em relação a mim, sua professora, antes da minha conclusão (quase) final.

\section{Um fio nas histórias secretas da Manoela, da Kamilly Vitória e do Everton}

Primeiro, apresento a Manoela, a Kamilly Vitória e o Everton, expondo textos de campo que mostram como os conheci melhor quando eram meus alunos do sexto ano. Como eu disse anteriormente, as postagens feitas no Edmodo foram parte dos textos de campo que investiguei para atingir meus objetivos de pesquisa. Neste item, exponho algumas imagens da tela do computador, com características relevantes, como datas, fotografias e a linguagem que cada um decidiu usar para participar do grupo virtual. Na sequência, há alguns modos de como eles se descreviam para mim, sua professora, e para os colegas de sala.

A Manoela era uma aluna que, no início de 2014, não tinha conseguido escrever seu perfil no caderno, em sala de aula, durante uma atividade com esse gênero. Quando fui até sua carteira, no fundo da sala, e conversei com ela, percebi que não conseguia enxergar o texto que eu tinha escrito no quadro e que deveria servir como modelo. Em 23 de março de 2014, Manoela postou seu perfil, em inglês, no Edmodo. Foi uma superação, desde o dia que sua mãe a levou ao oftalmologista e durante a sequência didática que desenvolvemos, com base no gênero perfil.

\section{Manoela C. disse 23 março, 2014}

Hello!My is Manoela Costa Correia.My favorite color is purple.My favorite sport is voleyball.My favorite celebrity is Justin Bieber.I'm 11 years old.I study at Escola Municipal Professor Otávio Batista Coelho Filho.I live in Uberlândia, Minas Gerais ,Brazil.

A Manoela tinha muita dificuldade com as outras matérias da escola. Entretanto, depois dessa produção, ela foi ganhando cada vez mais confiança nas aulas de língua inglesa. Leu diversos textos em inglês e desenvolvia as atividades propostas com engajamento. Produziu, além do perfil, uma avatar que falava inglês, uma nuvem de palavras utilizando poemas de alunos do Reino Unido e uma legenda de fotografias. Todo o trabalho realizado por ela está bem detalhado em Bengezen (2017).

A Kamilly Vitória também é participante de pesquisa e foi autora de textos em língua inglesa. O que chama a atenção na autoria da Kamilly é a singularidade. Ela, durante as aulas, tirava todos ao seu redor da zona de conforto. Como professora, era intrigante sua imaginação, criatividade e segurança. Quanto mais ela se sentia livre para produzir textos, mais ela ousava, e estava sempre pronta para esclarecer sobre o que escrevia, como se sentia e por que fazia certas escolhas. Partindo da leitura de poemas de uma escritora mexicana que ela mesma tinha descoberto por conta própria, na internet, Kamilly chegou à versão final do seu próprio poema, no dia três de setembro de 2014, e compartilhou no Edmodo.

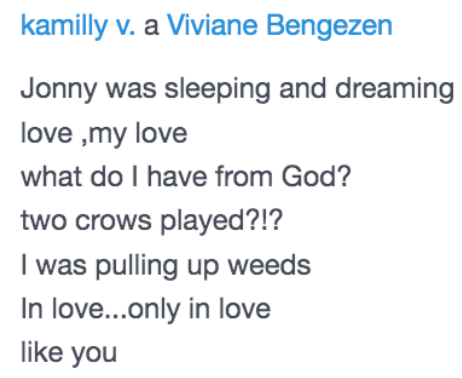


O Everton era um aluno que tinha repetido o sexto ano. Naquela escola, se um aluno fosse reprovado em uma única disciplina, ele deveria repetir todo o ano. A tensão nas histórias do Everton era porque ele tinha sido reprovado em Português, mas durante as aulas de Inglês, tinha se revelado um escritor seguro, proficiente no uso das tecnologias digitais e sempre disposto a me ajudar e os colegas de sala. Exercia um protagonismo na paisagem da escola e era admirado pelos colegas.

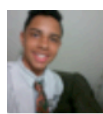

Everton M. to Uberlândia Views and Voices

Hello!My name is Everton .My favorite color is white .My favorite band is AC/DC.My favorite sports is Capoeira .My favorite TV Show is I Carly .My birthday is in february .My best friend is Ludmila, Isabella, lohann. I have one sister Brunna. My celebrity is Gr. Corrisco. I'm 13 years old. I' m from Monte Carmelo, Minas Gerais, Brasil. I study at Escola Municipal Professor Otávio Batista Coelho Filho and I am in 6th grade. I live in Uberlândia,Minas Gerais,Brazil. I am a Chelsea fan. I'm anxious,organized,crazy,funny and Happy! I love chocolate, ice cream and lasagna! I love English class, physical education and arts. Bye And that was my profile! Show Less

Likes - Reply - Share • Follow

As postagens da Manoela, da Kamilly Vitória e do Everton, no Edmodo, nos ajudam a compreender narrativamente as experiências de autoria dos alunos, nas aulas de língua inglesa, ao usarem tecnologias digitais para lerem e produzirem textos em inglês. Eu me posiciono conforme uma área de estudos do currículo fundamentados no conceito de experiência e nos critérios de experiência - continuidade e interação de Dewey (1938) e nos conceitos de Schwab (1973) sobre currículo como um curso de vida, constituído pelo aluno, professor, matéria escolar e o contexto dentro e fora da escola.

No Brasil, a maior parte dos estudos relacionados a autoria tem sido desenvolvida na área do ensino e aprendizagem de língua portuguesa, baseada nos estudos foucaultianos em análise do discurso, além de outras perspectivas pós-estruturalistas. Na Linguística Aplicada, o foco tem sido no produto produzido pelo aluno ou pelo professor, com pouco ou nenhum interesse em COMO os indivíduos se sentiram enquanto produziam textos ou qual é o processo de escrita nas escolas e universidades. Quase todas as pesquisas focam na autoria dos textos finais, mas não nas experiências de produzir esses textos.

Nesta pesquisa narrativa, contudo, meu foco não foi o texto final produzido pelo aluno, mas eu estava interessada no processo, em como eles viveram as experiências de escrita e de autoria em língua inglesa, usando tecnologias digitais. Considerando as experiências (MORRIS, 2001) da Manoela, da Kamilly Vitória e do Everton, de alunos que não se encaixavam aos padrões estabelecidos pela escola nas outras matérias, penso que foram experiências deseducativas (DEWEY, 1938). Everton me disse como ele se sentia em relação a diferentes espaços na paisagem da escola, em relação a diferentes professores:

As aulas de Inglês, para mim, eram uma coisa boa, onde a gente não era obrigado a escrever só o que a professora queria, mas o que a gente queria. Com a professora Viviane, tinha várias dinâmicas, íamos toda semana ao laboratório de Informática, escrevíamos vários textos e escolhíamos o que escrever. A gente tinha liberdade para escrever. Eu podia mostrar e expressar aquilo que eu sentia. (Texto de campo: conversa de WhatsApp entre Viviane e Everton, 13 de maio de 2016). 
Ao analisar minhas notas de campo, conversas com a Manoela, Kamilly e Everton, textos produzidos e compartilhados por eles e as histórias que vivemos e narramos na escola, comecei a refletir sobre o espaço do laboratório de Informática, a autoria discente, a ética relacional e o sentimento de pertencer que eles tinham nas nossas aulas. Elas aconteciam na sala de aula e no laboratório de Informática. Os alunos se divertiam com os computadores e brincavam com as estruturas da língua inglesa, fazendo colagens (BENGEZEN, 2017), lendo e produzindo textos e se comunicando pelo Edmodo, seguindo sequências didáticas com base em gêneros, na perspectiva de Cristóvão e Beato-Canato (2016).

\section{As tecnologias digitais nas nossas aulas de Inglês}

A Manoela, a Kamilly e o Everton usaram as tecnologias digitais como apoio: um complemento e uma forma de se conectar com pessoas a distância. Sobre um dos gêneros que estudamos, o perfil, os alunos leram diversos perfis, identificando o contexto cultural em que esse gênero funciona, a quais propósitos comunicativos serve, e como suas estruturas refletiam as funções. Ao longo de três meses, nós nos engajamos na sequência didática, negociamos, aprendemos, construímos sentidos, conversamos, fizemos anotações, escrevemos versões, editamos e então produzimos a versão final do nosso perfil. Um dos usos para nosso perfil era se apresentar nas redes sociais para falantes de inglês, ou para procurar parceiros que quisessem aprender português e nos ensinar inglês, como no Tandem.

Os colegas do Everton costumavam pedir ajuda a ele para usar a internet nas aulas:

Eu acho que tenho mais valor nas aulas de Inglês, porque a Viviane leva muito a gente para o laboratório. Eu adorei criar um avatar que falava inglês. Eu gostava de terminar minhas tarefas rapidinho, para levantar da minha cadeira e ir até meus colegas para ajudá-los. No Edmodo, assim que postei meu avatar, uma colega já me pediu ajuda. Eu gostava dessa posição de quem sabe fazer coisas e é popular na escola. Entretanto, acho que os outros professores não me viam dessa forma. Em geral, eu me sentia um fracasso, por ter repetido de ano (Texto de campo: conversa entre Viviane e Everton, 14 de maio de 2016).

Pelas conversas que tive com a Manoela e a Kamilly Vitória e pelas histórias que vivemos e narramos naquela paisagem, entendo que eles não se sentiam valorizados nos outros espaços da escola, como se sentiam no laboratório com os computadores. Kamilly flava muito em poder ser criativa, Everton destacava poder ser livre e Manoela, confiante e feliz. Eles se posicionavam como escritores e como quem sabe das coisas, usando a tecnologia para ler textos autênticos em língua inglesa e poder se comunicar com pessoas de outros países, falantes de outras línguas, utilizando a língua inglesa (algo inimaginável trinta anos atrás, quando eu era aluna do sexto ano). Houve uma interação entre mim, a Manoela, a Kamilly Vitória e a tecnologia. A tecnologia era parte desse lugar de composição de identidades entrecruzadas (CLANDININ ET AL., 2006).

\section{Inclusão pelas tecnologias digitais: a escola e o hospital conectados}

A Lowise (in memoriam) também foi participante dessa pesquisa e foi autora de uma frase de camiseta ao final do ano letivo. Em março de 2014, ela postou seu perfil no Edmodo, em inglês. Ela nunca tinha estudado inglês, mas estabeleceu um relacionamento comigo pela internet. Ela seguiu as instruções, leu os perfis no Edmodo e produziu o seu próprio. 
My name is Lowise. I'm 10 years old. I am from Uberlândia and I live in Uberlândia. I have two brother, Ewerton and Mathews. I am single girl of the my family. I'm a student at Escola Municipal Professor Otávio Batista Coelho Filho. I do ballet and my favorite color is lilac. My best friend and Débora. I am beautiful, inteligent, and polite. My mother is Larissa and my father is Wanderley.

Unlike (1) • Reply • Share • Follow

Depois de produzir esse texto, ela criou um avatar que falava inglês usando o site Voki. Ela escolheu o personagem, a voz, o sotaque, digitou seu perfil em inglês e compartilhou o produto na internet. Lowise também conversava comigo por Skype e fazia as avaliações a distância, por passar praticamente todo o ano no quarto do hospital, durante o tratamento do câncer. Quando iniciei a escrita da minha tese de doutorado, comecei a me relacionar com a Larissa, mãe da Lowise, que considera importante contar a história da Lowise, e sua luta para criar oportunidades para que as crianças em tratamento hospitalar possam se conectar com as escolas, sentindo-se pertencendo à comunidade escolar e vivendo histórias de inclusão. Em 2015, quando eu não era mais professora da Lowise, o conselho de classe decidiu reprová-la, argumentando que a Lowise não tinha frequentado as aulas o suficiente e, portanto, não estava apta a passar para o sétimo ano. Alguns meses depois, ela faleceu.

$\mathrm{Na}$ escola, Lowise só tinha sido aprovada na disciplina Inglês. Algumas histórias que eram contadas sobre mim eram de uma professora que dava notas, mas quem acompanhou a história que eu e Lowise vivemos entendeu que ela tinha atingido os objetivos propostos para aquele ano letivo nas aulas de Inglês. A Larissa acompanhava o desenvolvimento da filha e me dizia que eu nunca deveria desistir de compartilhar essa história, pois mostra para outras crianças em tratamento hospitalar, seus pais, seus professores e os gestores escolares que é possível conectar crianças que estão matriculadas na escola, mas não podem frequentar as aulas. A Lowise se sentia importante e confiante quando desenvolvia as tarefas propostas, mesmo a distância, percebendo que conseguia acompanhar o que seus colegas estavam fazendo, realizar as atividades, fazer escolhas, criar e construir saberes. Enfim, ela viveu histórias de inclusão e de pertencimento, mesmo estando no hospital quase todo o tempo.

A história da Lowise é relevante para a área da Linguística Aplicada porque apresenta tensões relacionadas à criação de oportunidades de autoria pela escola, oportunidades de autoria para alunos em tratamento hospitalar, a compreensão que os professores têm sobre o que é ensinar e aprender e o uso das tecnologias digitais para promover a inclusão, o relacionamento entre alunos e professores e o desenvolvimento do sentimento de pertencer.

\section{Escrevendo histórias que nos constituem}

O modo como os participantes de pesquisa usaram as tecnologias digitais para ler e produzir textos orais e escritos na escola chamou minha atenção, pois eles assumiam papéis de protagonistas e de liderança. O currículo foi se constituindo à medida que nos relacionávamos, com cada um vivendo e narrando as histórias que nos constituíam, em diferentes espaços na paisagem da escola.

Os lugares dentro da sala de aula e fora da sala de aula são epistemologicamente e moralmente diferentes na paisagem do conhecimento profissional do professor (CLANDININ; CONNELLY, 1995). De acordo com esses autores, viver nesses dois lugares epistemologicamente diferentes na paisagem cria dilemas para o professor, pois dentro da sala de aula o professor encontra um lugar seguro para viver suas histórias, criados no 
relacionamento com seus alunos. Fora da sala de aula, nos contextos escolares, o professor não se sente seguro para viver e narrar suas histórias. Murphy (2004) escreveu sobre a inversão desses lugares para as crianças. Eu me pergunto como a Manoela, a Kamilly, o Everton e a Lowise se sentiam quando eram posicionados nesses dois lugares na paisagem de modos tão diferentes em relação à tecnologia.

Minha consideração sobre os locais que ocupavam na paisagem me desafiou a considerar a complexidade do relacionamento deles com a escola, que era sempre mediado pela tecnologia, e consequentemente afetavam a produção de seus textos. Eu me pergunto se, para eles, também haveria uma inversão de lugares na paisagem, em termos de espaços seguros e não seguros, como Murphy (2004) sugere, mas de um modo diferente: seriam os espaços virtuais onde nossas aulas aconteciam espaços seguros, onde eles se sentiam livres, confiantes e respeitados?

Eu compartilhei autoridade (OYLER, 1996) com os participantes de pesquisa enquanto eles criavam espaços de produção de textos em inglês no sexto ano. Quando eles viam que suas experiências estavam sendo valorizadas e suas histórias estavam sendo legitimadas, deixaram sua marca na paisagem da escola.

Everton, por exemplo, adorava percorrer o laboratório de informática e conversar com outros colegas, sempre disposto a ajudá-los a fazer as tarefas. A Lowise gostava de se envolver nas atividades pelo Edmodo, Facebook e Skype, mas enquanto ela estava no hospital durante o ano letivo, só compareceu às aulas três vezes pessoalmente. Todas as outras atividades foram desenvolvidas a distância usando tecnologias digitais. Manoela ficava mais quieta, tinha um jeito tímido de participar e Kamilly Vitória era muito extrovertida e me desafiava com seus poemas diferentes e criativos.

Considero a possibilidades desses alunos terem escrito histórias de vida diferentes, pois o que eles faziam não era o que a escola valorizava. A escola buscava alunos comportados, obedientes, que não questionavam, que memorizavam conteúdos para despejarem em provas. Esses alunos tinham seus ritmos respeitados, andavam entre as carteiras, falavam com os colegas, enviavam suas produções em dias diferentes e podiam escolher de quais gêneros queriam ser autores.

\section{A ética relacional nas paisagens digitais}

O Everton me disse que se ele tivesse sido mais atencioso e aprendido o conteúdo de cor, ele não teria repetido. Em outras palavras, exigindo dele uma reprodução do assunto ensinado, o qual ele não pôde fornecer, a escola havia impedido a autoria de Everton. Lowise achava que, se não estivesse doente e pudesse frequentar a escola regularmente, teria sido capaz de cursar o sétimo ano, embora alguns professores e coordenadores pensassem o contrário. Por outro lado, Everton e Lowise disseram que tinham mais liberdade para escrever nas aulas de Inglês. Eles podiam mostrar e expressar o que sentiam. A liberdade, nesse caso, promoveu a possibilidade de autoria.

Ao considerarmos as histórias dos alunos, começamos a entender que existem diferentes caminhos de autoria, e o caminho que se segue depende das histórias vividas e das relações construídas temporalmente em diferentes paisagens. Algumas das paisagens onde essa história aconteceu foram o laboratório de informática, o hospital e os espaços virtuais do Facebook, Edmodo e e-mail. De alguma forma, esses lugares não faziam parte da escola para eles, e nesse espaço eles podiam ser mais eles mesmos e por meio deles sentiam uma conexão comigo. Lowise estava no hospital quase todos os dias, mas participava pela internet. Fisicamente, ela estava muito fraca e não foi capaz de ir à escola. No entanto, apesar de estar no hospital, as tecnologias digitais permitiram que ela aprendesse e compartilhasse. 
Com o tempo, as paisagens onde esses quatro alunos e eu vivemos moldaram nossas histórias que nos constituem. Esses espaços eram a sala de aula, o espaço virtual onde trocávamos e-mails, o laboratório de informática e o pátio da escola. A relação entre mim, Manoela, Kamilly, Lowise e Everton, dentro e fora da escola, ajudou as crianças a confiarem em mim, a fim de viver suas experiências de escrever, refletir e construir seus conhecimentos práticos pessoais conforme Clandinin e Connelly (1995). A relação professor-aluno é fundamental para a construção de histórias que constituem alunos e professores. Recordando os critérios de experiência (DEWEY, 1938), continuidade e interação, entendo que nossas experiências com tecnologias digitais nas aulas de Inglês foram educativas, à medida que avançavam em direção a futuros empreendimentos de autoria. Se tivesse sido possível continuar trabalhando com esses participantes por mais alguns anos, imaginamos que eles teriam construído uma história forte de autoria, principalmente porque eles já haviam encontrado sua própria voz por escrito, além de deixarem sua marca no campo de pesquisa.

\section{Conclusões}

Quando iniciei essa pesquisa no início de 2014, tinha o foco de valorizar as experiências de ensinar inglês na escola pública e, neste artigo, busquei honrar as narrativas vividas e narradas naquela paisagem. Vivenciei tentativas de autoria docente ensinando Inglês usando tecnologias digitais, e, de forma ética e relacional, narrei as experiências de autoria vivenciadas pelos alunos, especialmente nas paisagens digitais. Investigando as histórias que vivi com os alunos, percebi que estava aprendendo a ser uma professora diferente. Eu estava mudando minha história como professora. Em contraste com as histórias de homogeneização e pasteurização que eu já havia experimentado como professora, comecei a pensar mais profundamente sobre as necessidades dos jovens brasileiros, cada um em sua própria especificidade, não percebidas por mim e muitas vezes não percebidas por outros professores, guiando-me a refletir sobre a inclusão como pertencimento, valorização e reconhecimento.

A Manoela, a Kamilly Vitória, o Everton e a Lowise me ajudaram a entender as histórias que viviam, criavam e escreviam. Vivenciamos histórias de sucesso, criando espaços seguros e viajando para os mundos uns dos outros, mas também vivenciamos histórias de fracasso. Ao entender essas histórias como tentativas de autoria, podemos apontar para o caráter transformador delas, reconhecendo e imaginando possibilidades futuras. Vivi experiências de autoria docente, valorizando o trabalho do professor da escola básica e pública, e os jovens também viveram experiências de autoria discente nas aulas de inglês. Esse é o aspecto relacional da criação de currículos: todos nós estávamos aprendendo juntos. As experiências ao lado dos jovens, muitas vezes em relação às tecnologias digitais, me ajudaram a compartilhar autoridade com eles e a criar espaços de escrita de língua inglesa no sexto ano.

A Manoela realizava as atividades propostas, se relacionava comigo e com os outros colegas de sala de forma educada e me ensinou um pouco mais sobre a ética relacional da pesquisa narrativa. Minha busca para saber como ela estava contando a história de ser autora foi fundamental para compreender mais profundamente a experiência de autoria que ela viveu. Em vez de julgá-la e pensar somente do meu ponto de vista, eu criei oportunidades para que ela contasse sua versão dos fatos, como aconteceu, por exemplo, quando ela não escreveu seu perfil porque não estava conseguindo enxergar.

A Kamilly Vitória ousava com sua criatividade e me desafiava a compor sentidos dos seus textos. Ela deixou sua marca de singularidade e autonomia e eu passei a compreender o seu processo de escrita quando investiguei mais de perto, no meu relacionamento com ela. Com ela, eu aprendi que preciso imaginar continuamente que existe um algo a mais que meus alunos estão fazendo e aprendendo. 
A Lowise deixou sua marca de persistência e luta, quando desenvolvia as tarefas e seguia em frente, sem se deixar abater, fazendo um esforço para pertencer à nossa comunidade de construção de conhecimento, e de otimismo quando usou cores que brilham no escuro na sua frase de camiseta. Ela foi autora de um perfil, um avatar e uma frase de camiseta, sempre buscando compartilhar quem ela era e quem ela estava se tornando, nos espaços do hospital, da escola e da família, mostrando que a inclusão também é necessária a alunos que estão longe da escola, mas podem se conectar e pertencer à comunidade da sala de aula. Com a Lowise e sua mãe, Larissa, eu aprendi principalmente a ouvir a história do outro e a validar essa história, prestar atenção, mostrar que se importa e lidar com a vulnerabilidade.

Everton sentia-se importante ao percorrer o laboratório de informática e conversar com os colegas, sempre disposto a ajudá-los com as tarefas. As tensões vivenciadas nas histórias de Everton se deviam principalmente ao fato de ele ser um estudante repetitivo que era visto por seus professores como um caso sem solução. Eu não entendia como um jovem como Everton, que escrevia histórias incríveis, ajudava seus colegas de classe e era um proficiente usuário de computador, poderia ter repetido o ano. Com ele, aprendi que a escola pode impedir a autoria, em vez de promovê-la.

As histórias de autoria docente e discente vividas por nós foram histórias de liberdade, protagonismo, singularidade, voz, assinatura, ética relacional e inclusão. Os fios percorreram nossas experiências juntos. Um fio pode ser encontrado em outro fio, e em sua tecelagem juntos uma vida é moldada. Nossas vidas podem ser entendidas no espaço relacional do outro.

Neste artigo, discuti autoria docente e discente, ensino e aprendizagem de inglês na escola pública e oportunidades de inclusão, criadas quando os alunos sentem que pertencem ao grupo, participam das atividades e são valorizados. Significativamente, as tecnologias digitais nos ajudaram a realizar isso de diversas maneiras e nos posicionaram em relação à paisagem educacional da escola como conhecedores, como pessoas com autoridade, que desenvolveram autoria. Espero que mais professores de línguas das escolas públicas brasileiras possam compartilhar narrativas de experiências vividas com seus alunos e que alunos de Letras possam se inspirar nessas histórias, conectando a universidade e a escola. Eu, Manoela, Kamilly Vitória, Lowise e Everton não estávamos apenas aprendendo inglês em um ambiente rico em tecnologia, mas também aprendendo sobre quem éramos e quem estávamos nos tornando e como nos posicionamos no mundo.

\section{Referências}

BEATO-CANATO, A. P. M. O desenvolvimento da escrita em língua inglesa com o uso de sequências didáticas contextualizadas em um projeto de troca de correspondências. Londrina, PR. Tese de Doutorado. Universidade Estadual de Londrina - UEL, 307 f. 2009.

BEATO-CANATO, A. P. M.; CRISTÓVÃO, V. L. L. Proposta de avaliação de sequências didáticas com foco na escrita. Calidoscópio. Vol. 10, n. 1, p. 33-48, jan/abr. 2012.

BENGEZEN, V. C. Ética relacional, formação e autoria docente na perspectiva da inclusão.

Linguagem: Estudos e Pesquisas, v. 22, n. 1, 2018.

BENGEZEN, V. C. Histórias de aprendizagem de língua inglesa e de formação de professores. 2010. 173 f. Dissertação (Mestrado em Estudos Linguísticos)-Instituto de Letras e Linguística, Universidade Federal de Uberlândia, Uberlândia, 2010.

BENGEZEN, V. C. (Org.). We are the authors. Disponível em: $<$ https://www.widbook.com/ebook/brazilian-authorship> Acesso em: 18 jun. 2016.

CLANDININ, J. D. (Ed.). Handbook of narrative inquiry: mapping a methodology. Thousand Oaks; London; New Delhi: Sage/University of Alberta, 2007.

Engaging in narrative inquiry. New York: Routledge, 2013. 
CLANDININ, J. D. et al. Composing diverse identities: Narrative inquiries into the interwoven lives of children and teachers. London: Routledge, 2006.

CLANDININ, J. D. et al. The Relational Ethics of Narrative Inquiry. Routledge, 2018. CLANDININ, D. J.; CONNELY, M. Pesquisa Narrativa: experiência e história em pesquisa qualitativa. 2 ed. rev. Tradução: GPNEP: Grupo de pesquisa narrativa e educação de professores. ILEEL/UFU. Uberlândia: EDUFU, 2015.

CLANDININ, D. J.; CONNELLY, F. M. Teachers' Professional Knowledge Landscapes:

Teacher Stories - Stories of Teachers - School Stories - Stories of Schools. Educational researcher, v. 25, n. 3, p. 24-30, 1996.

CONNELLY, F. M.; CLANDININ, D. J. Shaping a professional identity: Stories of educational practice. New York, NY: Teachers College Press, 1999.

CRISTOVÃO, V. L. L.; BEATO-CANATO, A. P. M. A formação de professores de línguas para fins específicos com base em gêneros textuais. DELTA. Documentação de Estudos em Linguística Teórica e Aplicada (Online), v. 32, 45-74, 2016.

CRISTÓVÃO, V. L. L.; SZUNDY, P. T. C. Projetos de formação pré-serviço do professor de língua inglesa: sequências didáticas como instrumento no ensino- aprendizagem. RBLA, Belo Horizonte, v. 8, n. 1, p. 115-137, jan./jul. 2008.

DEWEY, J. Experience and Education. New York: Kappa Delta Pi, 1938.

DOLZ, J.; SCHNEUWLY, B. Gêneros orais e escritos na escola. Tradução e organização:

Roxane Rojo e Glaís Sales Cordeiro. Mercado de Letras, 2004. 278 p.

LUGONES, M. Playfulness, "world"-travelling, and loving perception. Hypatia, 2(2), 3-19, 1987.

MELLO, D. M. Histórias de subversão do currículo, conflitos e resistências: buscando espaço para formação de professores na aula de língua inglesa no curso de Letras. 2004. 225 f. Tese (Doutorado) - Pontifícia Univesidade Católica de São Paulo, São Paulo.

. A Teacher's Story of Facing the Road of Change. Polifonia (UFMT), v. 19, p. 261$279,2012$.

. Developing Writing Skills and Composing: the challenge of writing in a foreign language. In: REICHMANN, C. L. (Org.). Diários Reflexivos de Professores de Línguas: ensinar, escrever, refazer(-se). 1ed. São Paulo: Pontes, 2013, v. 1, p. 223- 234.

. The Language of Arts in a Narrative Inquire Landscape. In: CLANDININ, D. J.

(Org.). Handbook of Narrative Inquiry: mapping a methodology. 1ed. Florida: Sage Publications Inc, 2007, v. 1, p. 203-223.

MELLO, D. M. et al. Coming to Narrative Inquiry In the Context of Our Lives: a conversation about our work as narrative inquirers. Revista Brasileira de Pesquisa (Auto)biográfica, v. 1, n.3, p. 565, 2016.

MINH-HA, T. T. Woman, native, other: Writing postcoloniality and feminism. Bloomington: Indiana University Press, 1989.

MORRIS, D. B. Narrative, ethics, and pain: Thinking with stories. Narrative, 9(1), 55-77, 2001. MURPHY, M. S. Understanding children's knowledge: A narrative inquiry into school experiences. Unpublished doctoral dissertation, University of Alberta, Edmonton, Alberta, 2004.

OYLER, C. Making Room for Students: Sharing Teacher Authority in Room 104. Teachers College Press, New York, NY, 1996.

SWALES, J. M. Genre analysis: English in academic and research settings. Cambridge: Cambridge University Press, 1990.

Research Genres: Explorations and Applications. Cambridge: Cambridge UP, 2004. . World of genre - Metaphors of genre. IV SIGET (Simpósio Internacional de estudos de gêneros textuais, 2007, Tubarão, SC. Anais. Tubarão: Unisul. 2007.

Submetido em 29/09/18

Aceito em 19/12/2018 